\title{
Collagen Analysis in Human Tooth Germ Papillae
}

\author{
Ivete Jorge ABRAHÃO ${ }^{1,2}$ \\ Manoela Domingues MARTINS 2,3 \\ Emílio KATAYAMA ${ }^{1}$ \\ João Humberto ANTONIAZZI ${ }^{1}$ \\ Angelo SEGMENTILLI ${ }^{2}$ \\ Márcia Martins MARQUES ${ }^{1}$ \\ ${ }^{1}$ Department of Endodontics, School of Dentistry, University of São Paulo, São Paulo, SP, Brazil \\ ${ }^{2}$ School of Dentistry, Metropolitan University of Santos, Santos, SP, Brazil \\ ${ }^{3}$ School of Dentistry, Rehabilitation Postgraduate Program, Nove de Julho University, São Paulo, SP, Brazil
}

\begin{abstract}
The extracellular matrix (ECM) performs a very important role in growth regulation and tissue differentiation and organization. In view of this, the purpose of this study was to analyze the collagen, the major organic component of dental pulp ECM, in papillae of human tooth germs in different developmental phases. The maxillas and mandibles of 9 human fetuses ranging from 10 to 22 weeks of intrauterine life were removed and 16 tooth germs ( 1 in the cap stage, 8 in the early bell stage and 7 in the late bell stage) were obtained. The pieces were processed for histological analysis and stained with hematoxylin-eosin, Masson's Trichrome and picrosirius staining technique. Both types of collagen in the dental papilla were only detected by the picrosirius staining technique under polarized light microscopy. Type III collagen was detected in all specimens. Type I collagen was present in focal areas of the dental papilla only in some specimens. In conclusion, the findings of this study showed that type III collagen is a regular component of the papillae of human tooth germs whereas type I collagen is present in a significantly lesser amount.
\end{abstract}

Key Words: dental papillae, extracellular matrix, odontogenesis, type I collagen, type III collagen.

\section{INTRODUCTION}

The dental pulp is a connective tissue with a peculiar organization and location. It is surrounded by dentin, which is a hard and inelastic tissue. The dental pulp is composed of cells (fibroblasts, odontoblasts and undifferentiated mesenchymal cells) in contact with a complex chain of macromolecules secreted extracellularly, which form the extracellular matrix (ECM) (1). In addition to providing a structure for the tissues, this matrix has a bioactive role in the regulation of cell behavior, influencing its development, migration, proliferation, form and function (2).

The main macromolecules in dental pulp ECM are collagenous proteins (especially types I and III collagen), non-collagenous proteins (fibronectin, tenascin, osteonectin, sialoprotein and osteocalcin) and proteoglycans, including hyaluronic acid, chondroitin sulfate, heparan sulfate and phospholipid (1-4).

Collagen constitutes nearly 34\% of the total ECM proteins and type I and III collagens are the most predominant types. Type I collagen, most commonly found in dense conjunctive tissues, is necessary for tissue architecture stabilization, while type III collagen, most commonly found in loose conjunctive tissues, has an important function in tissue elasticity $(5,6)$.

Type I collagen is the most abundant protein in mineralized tissues, except for enamel, and is also the main ECM organic component. It has been suggested that this protein may be either involved in odontoblastic differentiation or a component of predentin secreted by polarized odontoblasts $(7,8)$. Type I collagen has been identified in dental papilla during dental organ development, predentin, intertubular and reparative dentin and

Correspondence: Profa. Dra. Márcia Martins Marques, Departamento de Endodontia, Faculdade de Odontologia, Universidade de São Paulo, Av. Prof. Lineu Prestes, 2227, 005508-900 São Paulo, SP, Brasil, Tel/Fax: +55-11-3091-7839. e-mail: mmmarques@usp.br 
human pulp fibroblast culture (9-13).

There are few studies addressing human dental pulp development. In addition, most previous studies were done in rodents and their application in humans is limited. There are no published data referring to the presence and distribution of ECM components, such as collagen, in human dental papillae.

Because ECM has a relevant role in growth regulation and tissue differentiation and organization, the purpose of this study was evaluate the main component of ECM, collagen, in the dental papilla of tooth germs of human fetuses.

\section{MATERIAL AND METHODS}

Tooth germs were obtained from 9 human fetuses (forensic post-mortem) ranging from 10 to 22 weeks of pregnancy. Parental written informed consent was given and the project was approved by the Ethics in Research Committee of the Metropolitan University of Santos.

In each case, the maxillas and mandibles were carefully dissected, fixed in $10 \%$ buffered formalin and demineralized with formic acid (14). The pieces were rinsed in distilled water, bisected into left and right halves, dehydrated, embedded in paraffin and serially sectioned longitudinally. Five-micrometer-thick cuts were obtained and stained with hematoxylin-eosin (HE) for routine histological examination.

As tooth formation occurs during a large timespan, the developmental stage of individual tooth germs is poorly related to gestation time. Therefore, in this study, the evaluation of the specimens was related to tooth germ developmental stages and not fetal age. Collagen was analyzed by Masson's Trichrome and Picrosirius (Sirus Red) histochemical methods (15) under light and polarized microscopy, respectively.

\section{RESULTS}

Sixteen tooth germs were obtained from the 9 human fetuses. No specimen exhibited germs in the bud stage. The sample was composed of 1 germ in the cap stage, 8 in the early bell stage and 7 in the late bell stage. The morphological aspects of the different human tooth germ developmental stages are illustrated in Figure 1.

The results of histochemical analysis are show in Figures 2 to 4 . In the specimens stained by Masson's
Trichrome (Fig. 3), collagen fibers were not observed in the dental papilla, regardless of the phase of tooth germ development. These fibers were found in the connective tissue of gingiva, alveolar bone and dentin.

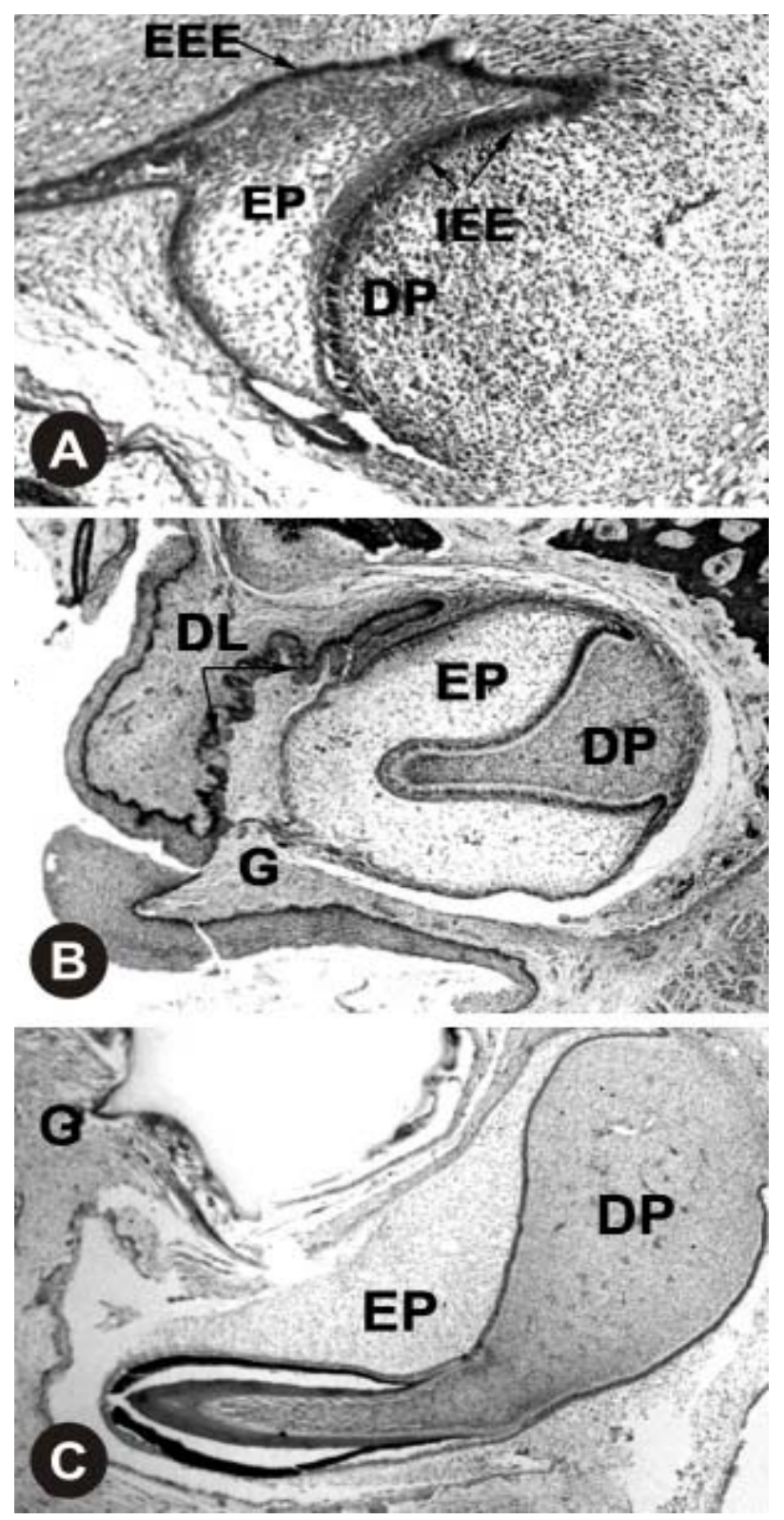

Figure 1. Photomicrographs of human tooth germs at three developmental stages. A (cap stage): external enamel epithelium (EEE), inner enamel epithelium (IEE), enamel papilla (EP) and dental papilla (DP). B (early bell stage): dental papilla (DP), enamel papilla (EP), dental lamina (DL) and gingiva (G). C (late bell stage): dental papilla (DP), enamel papilla (EP) and gingiva (G). HE (original magnifications: A: X100; B: X40; C: X40). 
Collagen was found only in specimens stained by Picrosirius under polarized microscopy (Fig. 4). Type I collagen appeared as thick yellow or red fibers present in a large amount in dentin (Fig. 4A) and in the connective tissue of gingiva (Figs. 4A and B). Little amount of type I collagen was detected in the tooth germ papilla and only in some specimens (Figs. 2 and 4B). This collagen appeared as short red fibers in focal areas of tooth germ papilla, underneath the inner enamel dental epithelium (Fig. 4B).

Type III collagen was detected in all samples. This collagen appeared as delicate green-stained fibers and arranged in a parallel fashion and homogeneously distributed in tooth germ papilla (Fig. 4B). This type of collagen was also present in the connective tissue of the gingiva and dental follicle. Both types of collagen were absent in the enamel papilla.

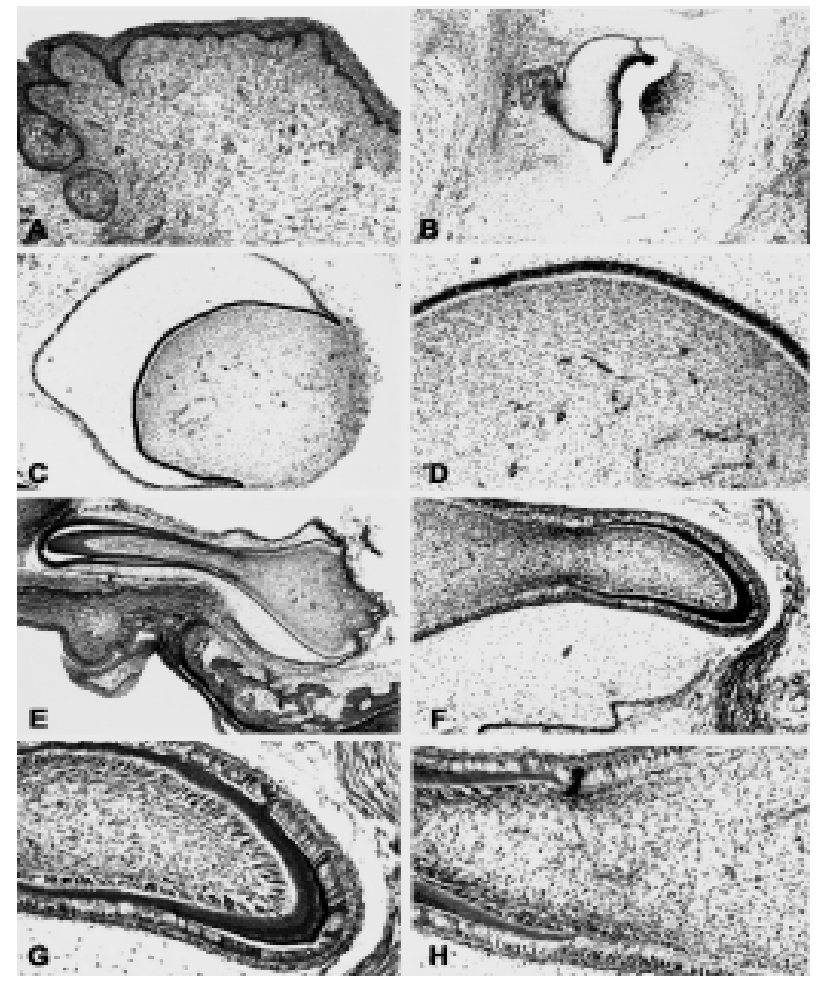

Figure 3. Photomicrographs of human fetuses stained by Masson's Trichrome. A: oral mucosa with blue-stained collagen fibers. B: dental germ in cap stage. C: tooth germ in early bell stage. D: close-up view of $\mathrm{C}$ depicting the dental papilla devoid of blue-stained collagen fibers; E-F: late bell stage showing collagen only in dentin, dental follicle, gingiva and alveolar bone. E-H: absence of collagen fibers in dental papilla (original magnifications: A, C and F: X100; B and E: X40; D, G and H: X200).

\begin{tabular}{|c|c|c|c|c|c|c|c|c|c|c|}
\hline \multirow{2}{*}{$\begin{array}{l}\text { Specimens } \\
\qquad(n=16)\end{array}$} & \multirow{2}{*}{$\begin{array}{c}\text { Developmental } \\
\text { phase }\end{array}$} & \multicolumn{3}{|c|}{ Dental Papilla } & \multicolumn{3}{|c|}{ Gingiva } & \multicolumn{3}{|c|}{ Dental Follicle } \\
\hline & & MT & PS(1) & PS(iil) & MT & PS(1) & PS(III) & MT & PS(1) & PS(III) \\
\hline 1 & EB & . & , & 4 & $4+4$ & + & 4 & 4 & 4 & + \\
\hline 2 & & . & , & • & $* *$ & + & + & + & + & + \\
\hline 3 & EB & . & . & • & $*+$ & + & • & + & + & + \\
\hline 4 & EB & . & + & + & $4+$ & + & 4 & $*$ & 4 & + \\
\hline 5 & EB & . & . & + & $++t$ & + & + & + & + & + \\
\hline 6 & EB & . & . & + & t+t+ & + & + & + & + & + \\
\hline 7 & LB & . & , & + & $4+$ & + & 4 & * & 4 & + \\
\hline 8 & LB & . & + & 4 & $4+4$ & + & 4 & $\$ 4$ & + & + \\
\hline 9 & LB & . & . & + & $+4+4$ & + & 4 & + & + & + \\
\hline 10 & LB & . & + & • & $* * *$ & + & • & + & * & + \\
\hline 11 & LB & . & . & • & $* * *$ & + & • & • & • & + \\
\hline 12 & LB & . & , & 4 & $4+4$ & + & 4 & + & 4 & + \\
\hline 13 & LB & . & . & 4 & $+4+4$ & + & 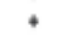 & +4 & 4 & + \\
\hline 14 & LB & . & . & + & +++ & + & + & + & + & + \\
\hline 15 & LB & . & . & 4 & 44 & + & 4 & + & 4 & + \\
\hline 16 & $\mathrm{C}$ & . & . & + & 44 & + & + & + & 4 & + \\
\hline
\end{tabular}

Figure 2. Histochemical analysis of the tooth germs. EB: early bell stage; LB: late bell stage; C: cap stage; MT: Masson's Trichrome; PS(I): type I collagen by Picrosirius staining technique; PS(III): type III collagen by Picrosirius staining technique; (-) absent; (+) scarce; $(++)$ present; $(+++)$ abundant.
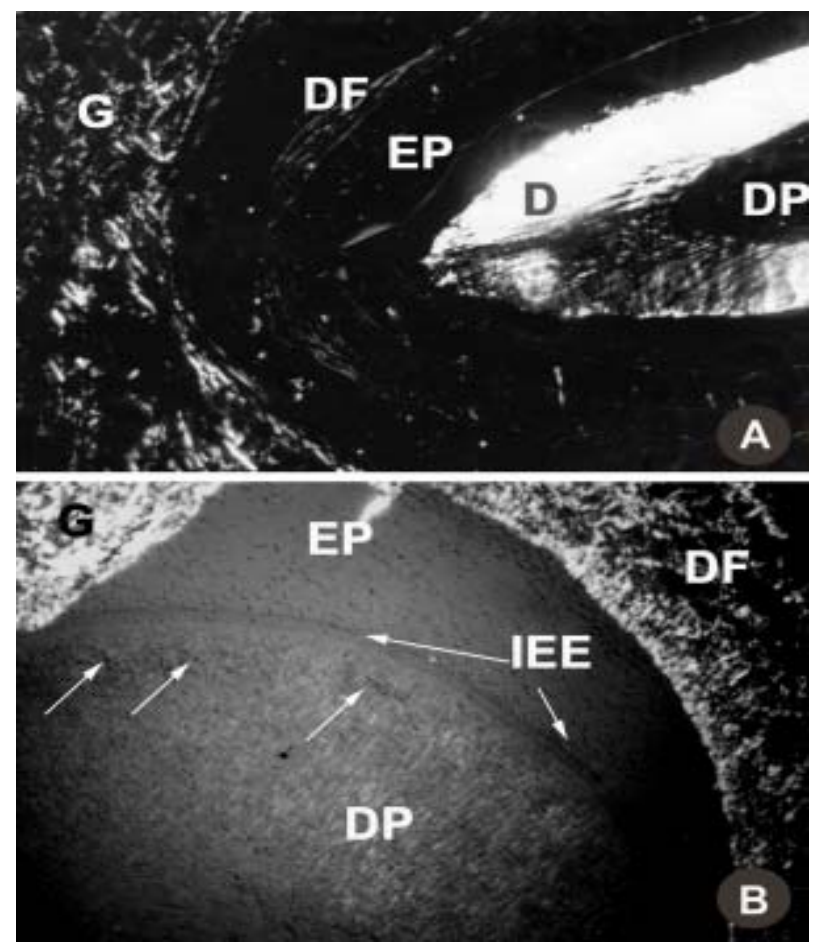

Figure 4. Polarization photomicrographs of human tooth germs in late (A) and early (B) bell stages. A: grey-stained type III collagen in gingiva (G) and dental follicle (DF). White-stained type I collagen in dentin (D). These fibers are absent in dental papilla (DP) and enamel papilla (EP). B: white-stained type I collagen in gingiva (G) and focal areas (arrows) of dental papilla (DP) underneath the inner enamel epithelium (IEE). In the dental follicle (DF) and gingiva (G) white type I collagen fascicles are intermingled with more delicate grey type III collagen fibers. 


\section{DISCUSSION}

The presence and distribution of collagenous proteins in human dental papilla was analyzed. Types I and III collagens were observed in the tooth germ papilla of human fetuses. However, type I collagen was found in a lesser amount than type III and observed only in some specimens.

Two histochemical methods were used for detection of collagen: Masson's Trichrome and Picrosirius staining under polarized microscopy. In the tooth germ papilla, this protein was only detected by Picrosirius staining, which is a specific method for collagen detection. This technique allowed detecting the presence of type III collagen, which was abundantly distributed in a homogeneous fashion, regardless of the stages of tooth germ development. This type of collagen was present in the dental papilla, dental follicle and gingiva. These results obtained for type III collagen were already expected because the presence of type III collagen in tooth germ papillae and dental pulp of erupted teeth has been widely reported. However, most of those studies were performed in non-human species $(7,12,16)$. The findings of the present confirmed the presence of type III collagen in the ECM of human dental papilla.

Birefringent type I collagen fibers were abundantly detected in the gingiva as red or yellow thick fascicles on sections stained by the Picrosirius method. On the other hand, in the dental papilla, these collagen fibers were found in a small number and only in focal areas of some specimens. The results of the sections stained by Masson's Trichrome did not confirm these findings. Although in these sections blue collagen fascicles were abundantly found in the gingiva, tooth germ papilla collagen was not detected. This probably occurred because Masson's Trichrome technique is not specific for collagen detection, especially when this protein is present in small amounts.

Type I collagen appeared in focal areas of the dental germ papilla, underneath the inner enamel dental epithelium. It is exactly the region of the dental papilla where the pre-odontoblasts are situated. This result support the idea that this collagen synthesis could be a significant step in odontoblastic differentiation process $(16,17)$.

Type I collagen was found in the predentin, which was expected, because this protein has already a well established function. A large number of studies showed that collagen works as a guide in mineralization progression throughout its long axis $(11,18)$.

The presence of type I collagen is common in tissues subjected to tension, such as skin and bones (2). During odontogenesis, the enamel organ is probably not subject to tissue tensions as erupted teeth or the tooth germ during the eruptive process (16). This might possibly explain why the examined dental papillae presented only minor type I collagen expression.

Hillmann and Geurtsen (11) investigated the distribution of the extracellular matrix molecules in human dental pulps of various ages using indirect immunofluorescence and polarized microscopy. The authors fund both type I and type III collagens. Other authors observed type I collagen not only in erupted teeth, but also in tooth germ papillae. However, those authors used more sensitive histological techniques, such as the immunohistochemistry. Using this technique, Garcia et al. (13) observed that type I collagen labeled the pulp of tooth germs less intensively than pulps of erupted teeth.

The concomitant analysis of type I and type III collagen in the human dental papilla has not yet been done. Most information available about collagen expression in tooth germ papilla refers to type I collagen because, in general, type I collagen is the protein of choice to be evaluated in immunohistochemical studies. In this study, however, the examination of sections by the Picrosirius-polarization method showed, by fiber color and morphology, both types of collagen in the same section. Type I collagen was situated under the pre-odontoblasts whereas type III collagen was homogeneously distributed throughout the tooth germ papilla. These results are consistent with the roles of each type of collagen on dental papilla, i.e., induction of odontoblastic differentiation (type I) and tissue elasticity (type III), which a property needed during the dental development. Therefore, further studies are required to better understand the participation of these proteins in tooth formation process.

In conclusion, the findings of this study showed that type III collagen is a regular component of the papillae of human tooth germs whereas type I collagen is present in a significantly lesser amount.

\section{RESUMO}

A matriz extracelular (MEC) tem um papel importante na 
regulação do crescimento e na diferenciação e organização dos tecidos. Com base nestes aspectos o objetivo do deste estudo foi analisar o colágeno, maior componente orgânico da MEC da polpa dentária, na papila de germes dentários humanos, em diferentes fases do desenvolvimento. Foram obtidos fragmentos de maxilas e mandíbulas de 9 fetos humanos com 10 a 22 semanas de vida intra-uterina, dos quais foram analisados 16 germes dentários (1 em estágio de capuz, 8 em estágio de campânula precoce e 7 em estágio de campânula tardia). Secções histológicas seriadas foram coradas com hematoxilina e eosina, tricrômico de Masson e técnica de coloração do picrosirius. Ambos os tipos de colágeno na papila dentária foram somente detectados pela técnica de coloração do picrosirius usando microscopia de luz polarizada. Colágeno tipo III foi detectado em todas as amostras. Colágeno tipo I estava presente em áreas focais da papila dental em algumas amostras. Concluiu-se que o colágeno tipo III mostrouse um componente regular da papila de germes dentários humanos, enquanto o colágeno tipo I esteve presente em quantidade significativamente menor.

\section{ACKNOWLEDGEMENTS}

This study was supported by The State of São Paulo Research Foundation (FAPESP), São Paulo, Brazil.

\section{REFERENCES}

1. Linde A. Session II: cells and extracellular matrices of the dental pulp. The extracellular matrix of the dental pulp and dentine. J Dent Res 1985;64:523-529.

2. Abrahamson DR. Recent studies on the structure and pathology of basement membranes. J Pathol 1986;149:257-278.

3. van Amerongen JP, Lemmens IG, Tomino GJM. The concentration, extractability and characterization of collagen in human dental pulp. Arch Oral Biol 1983;28:339-345.

4. Goldberg M, Lasfargues JJ. Pulpodentinal complex revised. J Dent 1995;23:15-20.

5. Narayanan AS, Page RC. Biochemical characterization of collagens synthesized by fibroblasts derived from normal and diseased human gingival. J Biol Chem 1976; 251:5464-5471.

6. Shuttleworth CA, Berry L, Wilson NHF. Collagen synthesis in rabbit dental pulp fibroblasts cultures. Arch Oral Biol 1980;25:201-205.
7. Andujar MB, Hartmann DJ, Emonard H, Magliore H. Distribution and synthesis of type I and type III collagens in developing mouse molar tooth root. Histochemistry 1988; 88:131-140.

8. MaoYQ, Ohsaki Y, Kurisu K. Immunohistochemical study of the relationship between extracellular matrix and root bifurcation in the mouse molar. Arch Oral Biol 1990;35:583-591.

9. Maglorie H, Jofre A, Hartmann DJ. Localization and synthesis of type III collagen and fibronectina in human reparative dentine. Histochemistry 1988;88:141-149.

10. Veron MH, Couble ML, Caillot G, Hartmann DJ, Maglorie H. Expression of fibronectin and type I collagen by human dental pulp cells and gingival fibroblast grow on fibronectin substrate. Arch Oral Biol 1990;35:565-569.

11. Hillmann G, Geurtsen W. Light-microscopical investigation of the distribution of extracellular matrix molecules and calcifications in human dental pulps of various ages. Cell Tissue Res 1997;289:145-154.

12. Webb PP, Moxham BJ, Ralphs JR, Benjamin M. Immunolocalisation of collagens in the developing rat molar tooth. Eur J Oral Sci 1998;106:147-155.

13. Garcia JMQ, Martins MD, Jaeger RG, Marques MM. Immunolocalization of bone extracellular matrix proteins (type I collagen, osteonectina and bone sialoprotein) in human dental pulp and cultured pulp cells. Int End J 2003;36:404-410.

14. Domingues MG, Jaeger MM, Araujo VC, Araujo NS. Expression of cytokeratins in human enamel organ. Eur $\mathrm{J}$ Oral Sci 2000;108:43-47.

15. Andrade, G. B. Correa, FR, Montes GS, Battlehner CN, Saldiva PHN. Dating of fibrotic lesions by the picrosirius-polarization method: an applications using the lesions of lechiguana (bovine focal proliferative fibrogranulomatous panniculitis). Eur J Histoch Pavia 1997;41:203-209.

16. Andujar MB, Couble P, Couble MI, Magliore H. Differential expression of type I and type III collagen genes during tooth development. Development 1991;111:691-698.

17. Ruch JV. Determinisms of odontogenesis. Cell Biol Rev 1987;14:1-99.

18. Karjalainen S, Soderling E, Pelliniemi L, Foidart JM. Immunohistochemical localization of types I and III collagen and fibronectin in dentine of carious human teeth. Arch Oral Biol 1986;31:801-806. 